\title{
Ipomoea batatas (L.) Lam.: A Rich Source of Lipophilic Phytochemicals
}

\author{
Nereida Cordeiro, ${ }^{* \dagger}{ }^{\dagger}$ Nélia Freitas, ${ }^{\dagger}$ Marisa Faria, ${ }^{\ddagger}$ and Manuela Gouveia ${ }^{\dagger}$ \\ ${ }^{\dagger}$ Competence Centre in Exact Science and Engineering and ${ }^{\ddagger}$ Competence Centre of Life Sciences, University of Madeira, \\ 9000-390 Funchal, Portugal
}

ABSTRACT: The lipophilic extracts from the storage root of 13 cultivars of sweet potato (Ipomoea batatas (L.) Lam.) were evaluated by gas chromatography-mass spectrometry with the aim to valorize them and offer information on their nutritional properties and potential health benefits. The amount of lipophilic extractives ranged from 0.87 to $1.32 \%$ dry weight. Fatty acids and sterols were the major families of compounds identified. The most abundant saturated and unsaturated fatty acids were hexadecanoic acid $(182-428 \mathrm{mg} / \mathrm{kg})$ and octadeca-9,12-dienoic acid $(133-554 \mathrm{mg} / \mathrm{kg})$, respectively. $\beta$-Sitosterol was the principal phytosterol, representing $55.2-77.6 \%$ of this family, followed by campesterol. Long-chain aliphatic alcohols and $\alpha$-tocopherol were also detected but in smaller amounts. The results suggest that sweet potato should be considered as an important dietary source of lipophilic phytochemicals.

KEYWORDS: sweet potato, lipophilic extractives, Ipomea batatas (L.) Lam., sterols, gas chromatography-mass spectrometry

\section{INTRODUCTION}

Sweet potato (Ipomoea batatas (L.) Lam., Convolvulaceae) is one of the most important root crops in the world, being cultivated in over 110 countries with a production of 104 billion tons. ${ }^{1}$ It is a traditional staple crop in tropical countries, although widely cultivated in subtropical and warm temperate regions. Sweet potato is mainly cultivated in Asia and Africa, whereas in Europe the crop is restricted to Portugal, Spain, Italy, and Greece. On Madeira Island, sweet potato has been important as a subsistence crop, ranked second in root and tuber crop production after potato with an estimated production of 10920 tons in 2012, part of which was exported. ${ }^{2}$ This commodity is highly productive and remarkably adapted to edaphic adverse conditions because it is relatively drought-tolerant; it thrives with low inputs and minimal horticultural practices. Natural hybrids, mutations, and artificial selection ${ }^{3}$ have resulted in the existence of a great number of cultivars that differ in morphological and phenotypic traits, such as leaf shape, root size and shape, and skin color. ${ }^{4}$

The storage roots are mainly used as staple food and animal feed and, to some extent, for industrial purposes. ${ }^{5,6}$ It is considered a source of energy due to their high carbohydrate content, accounting for about $85-90 \%$ of the dry matter. ${ }^{7}$ These carbohydrates comprise starch (58-76\%), sugars (sucrose, glucose, fructose, maltose), and smaller amounts of pectins, hemicelluloses, and cellulose. ${ }^{5}$ They are also excellent sources of vitamins (A, C, B-complex, E) and minerals (potassium, calcium, magnesium, zinc, copper). ${ }^{4,6}$ In addition, several studies have shown that sweet potato contains functional components such as $\beta$-carotene, polyphenols, and anthocyanins, which are important for human health. ${ }^{8,9}$ These phytochemicals have attracted attention as they display antioxidant ${ }^{8,9}$ anticarcinogenic, ${ }^{10}$ antimutagenic, ${ }^{11}$ and antihyperglycemic ${ }^{12}$ activities among other healthpromoting functions in humans.

The growing consumer demand for foods that, beyond their high sensory and nutritional quality, present benefits associated with health leads to the need for new ingredients that can meet these market requirements. Within this framework, the present study was undertaken as a part of a global project concerning nutritional and functional values of subtropical products, aiming to increase their economical valorization as well as providing relevant information to the direct consumption by humans or toward their effective utilization, particularly in the food industries.

Studies about the chemical composition of lipophilic extracts of sweet potato, growing on Madeira Island, have not been published until now. To bridge this gap, this work establishes the lipophilic extractive profile and the potential health benefits of 13 cultivars of sweet potato cultivated on Madeira Island.

\section{MATERIALS AND METHODS}

Plant Material and Sample Preparation. Thirteen cultivars of I. batatas (L.) Lam. (sweet potato), namely, 'Africa do Sul', 'Barbiça', 'Cabeira', 'Carocha', 'Cinco bicos', 'Escura', 'De peso', 'Preta, 'Rama de flor', 'Rama fina', 'Rama louca', 'Rebenta paredes', and 'Teixeira', grown on Madeira Island were kindly provided by ISOPlexis - Germobanco Agrícola da Macaronésia. From each cultivar 10 storage tubers were collected. Peels were discarded, and the flesh was cut into strips that were immediately frozen in liquid nitrogen and lyophilized. Dried strips were milled (40-60 mesh), and the powder was stored in the dark under vacuum for further analyses.

Extraction. Lipophilic compounds were extracted by Soxhlet using $20 \mathrm{~g}$ of freeze-dried sweet potato powder in $600 \mathrm{~mL}$ of dichloromethane for $6 \mathrm{~h}$. The solvent was dried by evaporation and the residue (extract amount) determined by gravimetry. The results were expressed in percentage of dry weight $(\mathrm{dw})$. All extractions were performed in triplicate with a variation of $<9 \%$.

GC-MS Analysis. The analysis was performed as described by Oliveira et al. ${ }^{13}$ Briefly, $20 \mathrm{mg}$ of each extract with internal standard (tetracosane) was dissolved in $250 \mu \mathrm{L}$ of pyridine. After the addition of $250 \mu \mathrm{L}$ of bis(trimethylsilyl)trifluoroacetamide and $50 \mu \mathrm{L}$ of trimethylchlorosilane, the mixture stood at $70{ }^{\circ} \mathrm{C}$ for $30 \mathrm{~min}$. The derivatized extract was analyzed by GC-MS, Agilent $6890 \mathrm{~N}$ gas chromatography coupled to a 5975 Agilent mass selective detector, equipped with a DB-1

Received: June 12, 2013

Revised: November 23, 2013

Accepted: November 27, 2013

Published: November 27, 2013 
J\&W capillary column $(30 \mathrm{~m} \times 0.25 \mathrm{~mm}$ inner diameter, $0.25 \mu \mathrm{m}$ film thickness). The chromatographic conditions were as follows: initial temperature, $80{ }^{\circ} \mathrm{C}$ for $5 \mathrm{~min}$; temperature rate, $4{ }^{\circ} \mathrm{C} / \mathrm{min}$; final temperature, $285^{\circ} \mathrm{C}$ for $10 \mathrm{~min}$; injector temperature, $290^{\circ} \mathrm{C}$; transferline temperature, $290{ }^{\circ} \mathrm{C}$; split ratio, $1 / 100$. The total run time was $66 \mathrm{~min}$.

The components with hydroxyl and carboxyl groups, converted into ethers and esters of trimethylsilyl (TMS), respectively, were identified on the basis of the comparison of their spectra with spectral libraries (NIST/EPA/NIH Mass Spectral Database, USA) and by comparing their fragmentation profiles with published data. ${ }^{13-15}$ For quantitative analysis, GC-MS was calibrated with pure reference compounds, representative of the major lipophilic extractives components (namely, hexadecanoic acid, 1-eicosanol, 16-hydroxyhexadecanoic acid, ferulic acid, and stigmasterol), relative to tetracosane used as internal standard.

For each sample (triplicate) two injections were performed, and results represent the average of six injections. The variation between injections was $<6 \%$.

Chemicals. 1-Eicosanol (98\% purity) and 16-hydroxyhexadecanoic acid (97\% purity) were supplied by Fluka Chemie (Madrid, Spain); bis(trimethylsilyl)trifluoroacetamide (99\% purity), dichloromethane ( $99 \%$ purity), tetracosane ( $99 \%$ purity), pyridine (99\% purity),

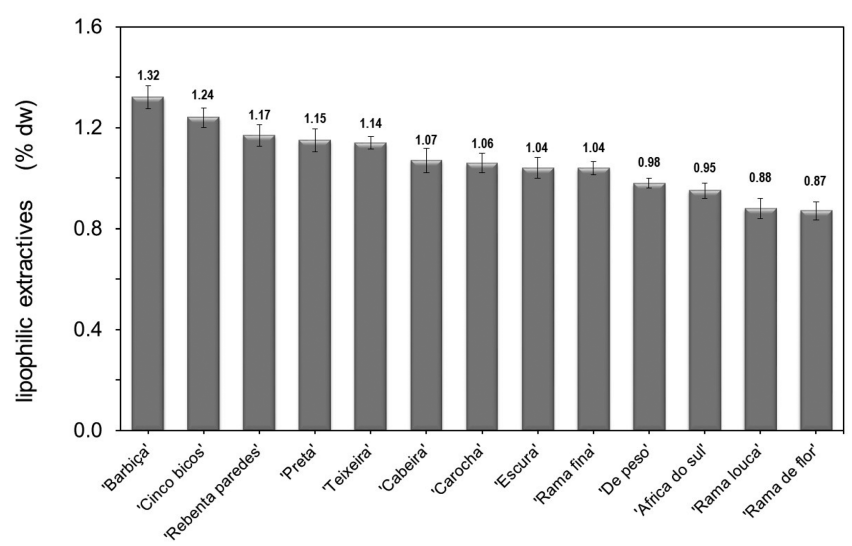

Figure 1. Dichloromethane extract yields from Ipomoea batatas (L.) Lam. cultivars of Madeira Island.
N,O-trimethylchlorosilane (99\% purity), hexadecanoic acid (99\% purity), ferulic acid (98\% purity), and stigmasterol (95\% purity) were purchased from Sigma Chemicals Co. (Madrid, Spain).

\section{RESULTS AND DISCUSSION}

In this work, 13 cultivars of sweet potato were analyzed by GC-MS to identify and quantify the lipophilic extractives present in the storage root of each cultivar. Dichloromethane was selected as a specific solvent for the extraction of lipophilic compounds. ${ }^{15}$ Among all of the sweet potato cultivars analyzed, 'Barbiça' and 'Cinco bicos' had the highest lipophilic extractives (1.32 and $1.24 \%$, respectively), followed by 'Rebenta paredes', 'Preta', and 'Teixeira' (Figure 1). The lowest lipophilic extractives were detected in 'Rama louca' and 'Rama de flor' (0.88 and $0.87 \%$, respectively). These variations might be due to factors such as qualitative composition of the cultivar, edaphoclimatic conditions, and maturity of the storage root.

A typical GC-MS chromatogram of the derivatized lipophilic extract is depicted in Figure 2 and reveals that fatty acids were predominant (peaks 31 and 36). The components present in the extracted fraction were identified, and their relative abundance is summarized in Table 1. Data indicate that sweet potato contained a high content of fatty acids followed by sterols and longchain aliphatic alcohols. The five major compounds identified were octadeca-9,12-dienoic acid, hexadecanoic acid, $\beta$-sitosterol, campesterol, and octadeca-9,12,15-trienoic acid.

Fourteen saturated fatty acids were identified against three unsaturated fatty acids (Table 1 ). The cultivars with the highest fatty acid content were 'Rama louca' ( $1289 \mathrm{mg} / \mathrm{kg}$ ) and 'De peso' $(1209 \mathrm{mg} / \mathrm{kg})$. In contrast, 'Teixeira' and 'Rama de flor' had the lowest fatty acids content ( 418 and $534 \mathrm{mg} / \mathrm{kg}$, respectively). Fatty acid percentage in the identified lipophilic extractives ranged between 65.8 and $84.0 \%$ for 'Rama de flor' and 'De peso' cultivars, respectively (Figure 3 ). The relative abundances of saturated and unsaturated fatty acids were similar among cultivars, although saturated fatty acids prevailed over unsaturated fatty acids (1.5-fold) in 'Rama fina'. Hexadecanoic acid was the most

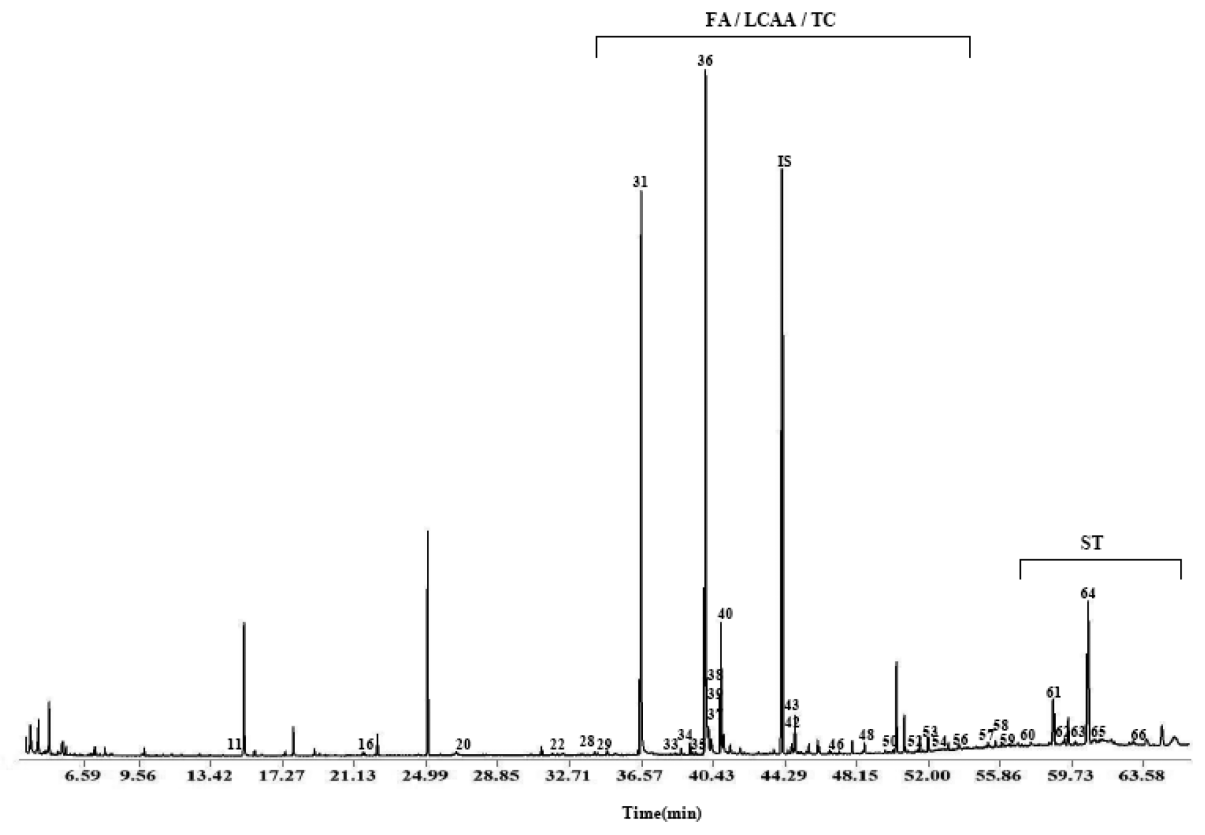

Figure 2. GC-MS chromatogram of the derivatized extract from cultivar 'De peso', obtained by a DB-1 30 m column. FA, fatty acids; LCAA, long-chain aliphatic alcohols; TC, tocopherols; ST, sterols; IS, internal standard. 
Table 1. Families and Compounds Identified in the Dichloromethane Extract of Sweet Potato Cultivars Grown on Madeira Island ${ }^{a}$

\begin{tabular}{|c|c|c|c|c|c|c|c|c|c|c|c|c|c|c|}
\hline peak & compound & $\begin{array}{l}\text { 'Africa do } \\
\text { Sul' }\end{array}$ & 'Barbiça' & 'Cabeira' & 'Carocha' & $\begin{array}{l}\text { 'Cinco } \\
\text { bicos' }\end{array}$ & 'Escura' & $\begin{array}{l}\text { 'De } \\
\text { peso' }\end{array}$ & 'Preta' & $\begin{array}{l}\text { 'Rama } \\
\text { de flor' }\end{array}$ & $\begin{array}{l}\text { 'Rama } \\
\text { fina' }\end{array}$ & $\begin{array}{l}\text { 'Rama } \\
\text { louca' }\end{array}$ & $\begin{array}{l}\text { 'Rebenta } \\
\text { paredes' }\end{array}$ & 'Teixeira' \\
\hline & fatty acids & 803 & 614 & 896 & 829 & 1106 & 612 & 1209 & 667 & 534 & 676 & 1289 & 768 & 418 \\
\hline & saturated & 437 & 322 & 419 & 427 & 533 & 359 & 587 & 332 & 261 & 406 & 662 & 425 & 247 \\
\hline 20 & dodecanoic acid & 1 & 1 & 4 & 3 & 1 & 1 & 3 & 2 & 1 & 1 & 1 & 3 & 1 \\
\hline 22 & tetradecanoic acid & 1 & 2 & 1 & 2 & 1 & 1 & 1 & 1 & 1 & 3 & 1 & 2 & 1 \\
\hline 28 & pentadecanoic acid & 1 & 1 & 1 & 1 & 2 & 83 & 2 & 1 & 1 & 3 & 2 & 1 & 1 \\
\hline 31 & hexadecanoic acid & 334 & 249 & 321 & 328 & 406 & 215 & 428 & 245 & 197 & 283 & 427 & 316 & 182 \\
\hline 34 & heptadecanoic acid & 3 & 3 & 4 & 4 & 4 & 3 & 5 & 3 & 2 & 4 & 4 & 2 & 2 \\
\hline 40 & octadecanoic acid & 50 & 26 & 38 & 37 & 73 & 23 & 91 & 25 & 21 & 34 & 50 & 40 & 23 \\
\hline 43 & eicosanoic acid & 13 & 13 & 15 & 14 & 21 & 9 & 28 & 14 & 10 & 10 & 21 & 14 & 8 \\
\hline 48 & docosanoic acid & 7 & 7 & 8 & 9 & 7 & 5 & 8 & 6 & 5 & 1 & 10 & 7 & 3 \\
\hline 50 & tricosanoic acid & 1 & 1 & 2 & 2 & 1 & 2 & 1 & 3 & 1 & 1 & 89 & 1 & 1 \\
\hline 53 & tetracosanoic acid & 9 & 6 & 7 & 10 & 9 & 5 & 11 & 9 & 7 & 7 & 15 & 11 & 5 \\
\hline 56 & pentacosanoic acid & 1 & 2 & 1 & 1 & 2 & 1 & 3 & 3 & 1 & 14 & 4 & 3 & 1 \\
\hline 57 & hexacosanoic acid & 1 & 1 & 2 & 7 & 3 & 4 & 4 & 4 & 4 & 1 & 8 & 7 & 1 \\
\hline 59 & heptacosanoic acid & 1 & 1 & 1 & 1 & 2 & 1 & 1 & 2 & 1 & 25 & 10 & 1 & 1 \\
\hline \multirow[t]{2}{*}{66} & triacontanoic acid & 14 & 9 & 14 & 8 & 1 & 6 & 1 & 14 & 9 & 19 & 20 & 17 & 17 \\
\hline & unsaturated & 366 & 292 & 477 & 402 & 573 & 253 & 622 & 335 & 273 & 270 & 627 & 343 & 171 \\
\hline 36 & octadeca-9,12-dienoic acid & 296 & 243 & 399 & 334 & 508 & 192 & 554 & 275 & 221 & 217 & 530 & 276 & 133 \\
\hline 37 & $\begin{array}{l}\text { octadeca-9,12,15-trienoic } \\
\text { acid }\end{array}$ & 57 & 40 & 62 & 54 & 37 & 30 & 20 & 52 & 43 & 41 & 79 & 48 & 27 \\
\hline \multirow[t]{2}{*}{38,39} & $\begin{array}{l}\text { octadec-9-enoic acid } \\
\quad \text { (cis and trans) }\end{array}$ & 13 & 9 & 16 & 14 & 28 & 31 & 48 & 8 & 9 & 12 & 18 & 19 & 11 \\
\hline & sterols & 267 & 231 & 288 & 213 & 228 & 186 & 214 & 264 & 252 & 245 & 475 & 279 & 174 \\
\hline 61 & campesterol & 53 & 46 & 54 & 54 & 51 & 35 & 48 & 61 & 43 & 61 & 101 & 74 & 39 \\
\hline 63 & stigmasterol & nd & 35 & 58 & 5 & 11 & 26 & nd & nd & 47 & 16 & 16 & 13 & 13 \\
\hline 64 & $\beta$-sitosterol & 199 & 145 & 176 & 154 & 166 & 125 & 166 & 187 & 139 & 168 & 358 & 192 & 122 \\
\hline \multirow[t]{2}{*}{65} & isofucosterol & 15 & 5 & nd & nd & nd & nd & nd & 16 & 23 & nd & nd & nd & nd \\
\hline & $\begin{array}{l}\text { long-chain aliphatic } \\
\text { alcohols }\end{array}$ & 29 & 20 & 34 & 19 & 16 & 29 & 17 & 23 & 23 & 57 & 40 & 21 & 24 \\
\hline 29 & hexadecan-1-ol & 3 & 4 & 8 & 4 & 1 & 3 & 3 & 3 & 3 & 6 & 2 & 4 & 4 \\
\hline 33 & $(Z)$-octadec-9-en-1-ol & nd & nd & 3 & nd & nd & nd & nd & nd & nd & nd & nd & nd & 3 \\
\hline 35 & octadecan-1-ol & 11 & 9 & 14 & 11 & 8 & 8 & 8 & 8 & 7 & 6 & 3 & 6 & 5 \\
\hline 46 & docosan-1-ol & 1 & nd & nd & nd & nd & nd & nd & nd & nd & 1 & nd & 1 & 3 \\
\hline 52 & tetracosan-1-ol & 2 & 5 & nd & 3 & 1 & 1 & 1 & nd & 1 & nd & nd & 1 & 2 \\
\hline 60 & octacosan-1-ol & nd & 1 & 1 & nd & 1 & 11 & nd & 3 & 2 & 1 & 5 & nd & nd \\
\hline \multirow[t]{2}{*}{62} & nonacosan-1-ol & 12 & 1 & 8 & 1 & 5 & 6 & 5 & 9 & 10 & 43 & 30 & 9 & 7 \\
\hline & tocopherols & nd & 2 & nd & 5 & 4 & 3 & nd & 7 & 3 & 10 & 9 & nd & nd \\
\hline 58 & $\alpha$-tocopherol & nd & 2 & nd & 5 & 4 & 3 & nd & 7 & 3 & 10 & 9 & nd & nd \\
\hline
\end{tabular}

${ }^{a}$ Results are the average of two injections for each sample $(\mathrm{mg} / \mathrm{kg} \mathrm{dw}, n=6)$. nd, not detectable.

abundant saturated fatty acid with abundances ranging from 182 to $428 \mathrm{mg} / \mathrm{kg}$ in 'Teixeira' and 'De peso' (33.1 and $43.5 \%$ of the total fatty acids content, respectively). Other identified saturated fatty acids included octadecanoic (21-91 mg/kg) and smaller quantities of eicosanoic, docosanoic, tetracosanoic, and triacontanoic acids. It is known that saturated fats are needed for energy, hormone production, cellular membranes, and organ padding. Hexadecanoic acid is one of the most common saturated fatty acid and one of the most prevalent saturated fatty acids in body lipids.

Fatty acids are major components of cell membrane structure and important for some vital biological processes, although particular attention has been given to polyunsaturated fatty acids, especially the $\omega-3$ and $\omega-6$ unsaturated fatty acids. The function of these essential fatty acids in human health is mainly associated with the prevention, delay, or treatment of chronic and acute diseases, such as cancer, cardiovascular diseases, osteoporosis, and immune disorders. ${ }^{16-18}$ Components such as octadeca-9,12dienoic and octadeca-9,12,15-trienoic acids are not synthesized by the human body ${ }^{16,17}$ and, being vital for metabolism, must come from food sources or diet supplements. In all cultivars analyzed the most abundant unsaturated fatty acids was octadeca-9,12-dienoic acid ( $\omega-6)$, with $31.4 \%$ in 'Escura' and $45.9 \%$ in 'Cinco bicos', followed by octadeca-9,12,15-trienoic acid $(\omega-3)$, which ranged from $1.7 \%$ in 'De peso' to $8.1 \%$ in 'Rama de flor'. These results are in agreement with previous studies, $^{7}$ which identify the octadeca-9,12-dienoic acid as the most abundant fatty acid (45.9\%), followed by hexadecanoic (34.6\%), octadeca-9,12,15-trienoic acid (7.1\%), octadecanoic (6.1\%), and octadec-9-enoic (1.3\%) acids.

The lipid composition of fruits and vegetables has lately received particular attention due to the special interest by 


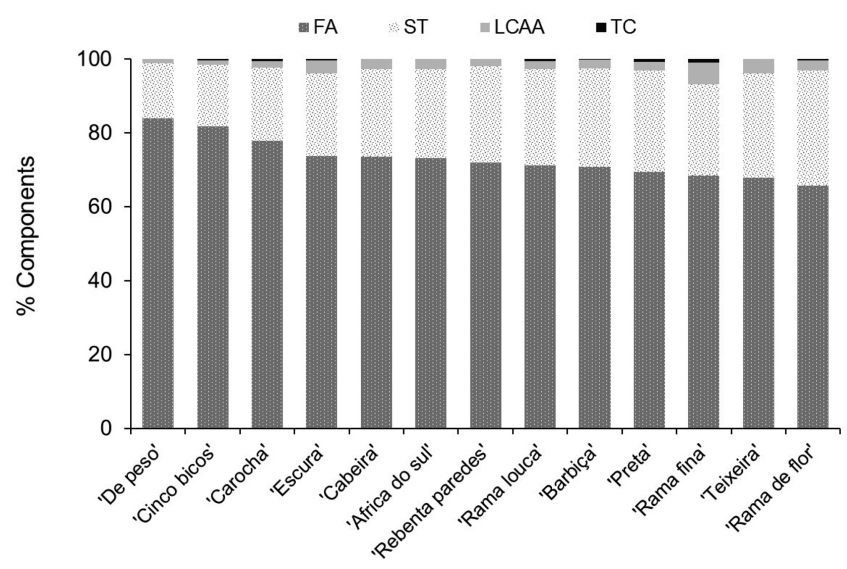

Figure 3. Major families of compounds in the dichloromethane extract from sweet potato cultivars. FA, fatty acids; LCAA, long-chain aliphatic alcohols; TC, tocopherols; ST, sterols.

consumers in essential fatty acids. Plant sources, that is, nuts, seeds, vegetables, legumes, grains, and fruits, are rich sources of lipids, and generally vegetable oils are a great source of octadeca9,12,15-trienoic acid and octadeca-9,12-dienoic acid. There is considerable variation in the fatty acid content in vegetable oils, and factors such as species, cultivar, variety, growing region, and climatic conditions have marked influences on the fatty acid profile. Compared with other vegetable oils, sweet potato is a good source of $\omega-3$ and $\omega-6$ fatty acids, with higher content $(\omega-3+\omega-6=40-53 \%$ in fatty acid composition) than found in seed oil from neem, rapeseed, and dragon lily (20-25\%), but similar to that found in sesame and pitaya seed or in green leafy vegetables from purslane, spinach, and buttercrunch lettuce. ${ }^{19}$

Sterols were the second largest family of lipophilic compounds present in the storage roots of sweet potato. Of the total lipophilic extractives identified the sterol content varied between 14.9\% ('De peso') and 31.0\% ('Rama de flor') (Figure 3). $\beta$-Sitosterol was the most abundant sterol (Figure 4). Among
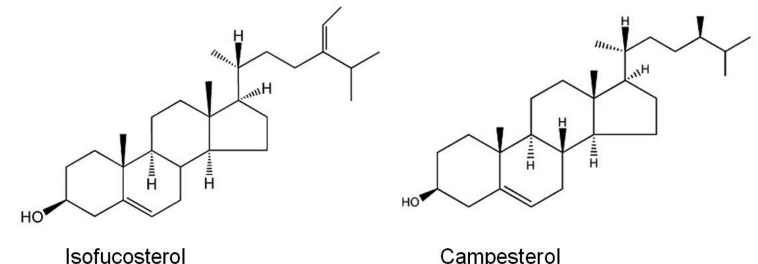

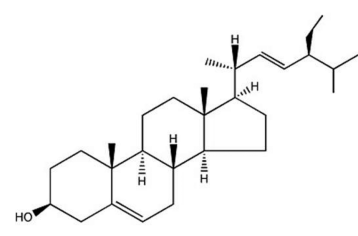

Stigmasterol

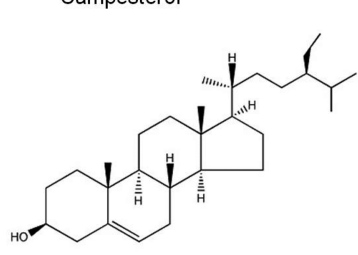

$\beta$-Sitosterol
Figure 4. Structures of the sterols identified in the sweet potato root.

cultivars, 'Teixeira' showed the lowest content, with $122 \mathrm{mg} / \mathrm{kg}$, and 'Rama louca' had the highest $\beta$-sitosterol content at $358 \mathrm{mg} / \mathrm{kg}$, resulting in a variability factor of 2.9 between the average $\beta$-sitosterol contents of the cultivars. Other sterols identified were campesterol $(35-101 \mathrm{mg} / \mathrm{kg})$, stigmasterol $(5-58 \mathrm{mg} / \mathrm{kg})$, and smaller quantities of isofucosterol (5-23 $\mathrm{mg} / \mathrm{kg}$ ), which was present only in 'Rama de flor', 'Preta',
'Africa do Sul', and 'Barbiça'. These values were generally similar to those found by Piironen et al. ${ }^{20}$ in a study that analyzed the sterol content of several vegetables, fruits, and berries. However, the content of $\beta$-sitosterol and campesterol in 'Rama louca' was higher than those reported for broccoli and cauliflower, the vegetables with the highest content. Thus, compared with fruits and some berries sweet potato is a good source of sterols. ${ }^{20}$

There are over 40 phytosterols identified, with the most prominent being $\beta$-sitosterol, campesterol, and stigmasterol. Phytosterols have potential effects on obesity, and high intakes of $\beta$-sitosterol, campesterol, and stigmasterol can also protect against atherosclerosis and prevent tumor growth. ${ }^{21,22}$ For example, campesterol is a phytochemical structurally similar to cholesterol that inhibits the absorption of cholesterol in the intestines and reduces low-density lipoprotein (LDL) cholesterol. Manufacturers started adding phytosterols to foods, such as margarines, that are designed for use as part of a cholesterollowering diet and for preventing heart disease. $\beta$-Sitosterol and campesterol are plant sterols that are added to foods to improve their ability to lower levels of total and LDL or "bad" cholesterol. The human intake of phytosterols must be 145-405 mg per day. ${ }^{18}$ Taken as an example, 'Rama de flor' could contribute $9 \mathrm{mg}$ of phytosterols per $100 \mathrm{~g}$ of fresh sweet potato.

In comparison to fatty acids and sterols the content of longchain aliphatic alcohols (LCAA) was less abundant, ranging from $1.2 \%$ ('Cinco bicos') to $5.8 \%$ ('Rama fina') of all identified compounds in the lipophilic fraction (Table 1). Of the seven LCAA identified, hexadecane-1-ol, octadecan-1-ol, and nonacosan-1-ol were present in all cultivars. 'Rama fina' and 'Rama louca' were the richest cultivars ( 57 and $40 \mathrm{mg} / \mathrm{kg}$, respectively) mainly due to the nonacosan-1-ol, which represented $75 \%$ of the total LCAA. The intake of LCAA has beneficial effects on health as they have been shown to play a role in cholesterol metabolism by lowering total cholesterol and LDL cholesterol and by raising high-density lipoprotein (HDL) cholesterol, ${ }^{23}$ giving protection against lipid peroxidation ${ }^{24}$ and mediators involved in inflammatory processes. ${ }^{25}$

Tocopherols were identified in eight cultivars of sweet potato (Table 1). Considerable amounts of $\alpha$-tocopherol, the most bioactive form of tocopherol elements (vitamin E), were detected in 'Rama fina' and 'Rama louca'. Similar amounts were found in vegetables and fruits, ${ }^{26}$ which are lower than those found in vegetable oils, nuts, and grains. ${ }^{27}$ Vitamin $\mathrm{E}$ is essential for human health as it is necessary for numerous physiological processes and thought to be a lipid-soluble antioxidant that prevents oxidative damage and reduces the risk of coronary heart disease, cancer, inflammatory diseases, and neurological disorders, among others. ${ }^{28}$

The experimental data showed large variations in total fatty acid, sterol, long-chain aliphatic alcohol, and tocopherol contents of the sweet potato cultivars assayed in this study. Among the cultivars, 'Rama louca' had the highest saturated and unsaturated fatty acid and sterol contents, in addition to high levels of longchain aliphatic alcohols and tocopherols. Nevertheless, other cultivars also have considerable levels of phytochemicals. Thus, the variability in the composition, the quantities of phytochemicals, and the availability of this information are important to help individuals make choices in the consumption of food crops seeking health benefits.

\section{AUTHOR INFORMATION}

\section{Corresponding Author}

*(N.C.) Phone: + 351291705 107. Fax: + 351291705149.

E-mail: ncordeiro@uma.pt. 


\section{Notes}

The authors declare no competing financial interest.

\section{ACKNOWLEDGMENTS}

We thank ISOPlexis - Germobanco Agrícola da Macaronésia for kindly providing the samples.

\section{ABBREVIATIONS USED}

GC-MS, gas chromatography-mass spectrometry; LCAA, longchain aliphatic alcohols; TC, tocopherols; ST, sterols; IS, internal standard; FA, fatty acids; TMS, trimethylsilyl; dw, dry weight; nd, not detected

\section{REFERENCES}

(1) FAO (Food and Agricultural Organization). http://www.faostat. fao.org/, 2012.

(2) INE - Instituto Nacional de Estatística, Portugal. Estatísticas Agrícolas 2012, http://www.ine.pt/, 2012.

(3) Srisuwan, S.; Sihachakr, D.; Siljak-Yakovlev, S. The origin and evolution of sweet potato (Ipomoea batatas Lam.) and its wild relatives through the cytogenetic approaches. Plant Sci. 2006, 171, 424-433.

(4) Woolfe, J. A. Sweet Potato, An Untapped Food Resource; Cambridge University Press: Cambridge, UK, 1992.

(5) Lebot, V. Tropical root and tuber crops: cassava, sweet potato, yams and aroids. Crop Production Science in Horticulture; CABI Publishing: Wallingford, UK, 2009.

(6) Mukhopadhyay, S. K.; Chattopadhyay, A.; Chakraborty, I.; Bhattacharya, I. Crops that feed the world 5. Sweetpotato. Sweetpotatoes for income and food security. Food Secur. 2011, 3, 283-305.

(7) Purcell, A. E.; Walter, W. M.; Wilson, L. G. Chapter 10, Quality and preservation of vegetables. In Sweet Potatoes; Eskin, N. A. M., Ed.; CRC Press: Boca Raton, FL, USA, 1989; pp 285-304.

(8) Teow, C. C.; Truong, V. D.; McFeeters, R. F.; Thompson, R. L.; Pecota, K. V.; Yencho, G. C. Antioxidant activities, phenolic and $\beta$ carotene contents of sweet potato genotypes with varying flesh colours. Food Chem. 2007, 103, 829-838.

(9) Rumbaoa, R. G. O.; Cornago, D. F.; Geronimo, I. M. Phenolic content and antioxidant capacity of Philippine sweet potato (Ipomoea batatas) varieties. Food Chem. 2009, 113, 1133-1138.

(10) Hagiwara, A.; Yoshino, H.; Ichihara, T.; Kawabe, M.; Tamano, S.; Aoki, H.; Koda, T.; Nakamura, M.; Imaida, K.; Ito, N.; Shirai, T. Prevention by natural food anthocyanins, purple sweet potato color and red cabbage color, of 2-amino-1-methyl-6-phenylimidazo[4,5- $b]$ pyridine (PhIP)-associated colorectal carcinogenesis in rats initiated with 1,2-dimethylhydrazine. J. Toxicol. Sci. 2002, 27, 57-68.

(11) Yoshimoto, M.; Okuno, S.; Yoshinaga, M.; Yamakawa, O.; Yamaguchi, M.; Yamada, J. Antimutagenicity of sweetpotato (Ipomoea batatas) roots. Biosci., Biotechnol., Biochem. 1999, 63, 537-541.

(12) Kusano, S.; Abe, H.; Tamura, H. Isolation of antidiabetic components from white-skinned sweet potato (Ipomoea batatas L.). Biosci., Biotechnol., Biochem. 2001, 65, 109-114.

(13) Oliveira, L.; Freire, C. S. R.; Silvestre, A. J. D.; Cordeiro, N.; Torres, I. C.; Evtuguin, D. Lipophilic extractives from different morphological parts of banana plant "Dwarf Cavendish". Ind. Crops Prod. 2006, 23, 201-211.

(14) Oliveira, L.; Freire, C. S. R.; Silvestre, A. J. D.; Cordeiro, N. Lipophilic extracts from banana fruit residues: a source of valuable phytosterols. J. Agric. Food Chem. 2008, 56, 9520-9524.

(15) Villaverde, J. J.; Oliveira, L.; Vilela, C.; Domingues, R. M.; Freitas, N.; Cordeiro, N.; Freire, C. S. R.; Silvestre, A. J. D. High valuable compounds form the unripe peel of several Musa species cultivated in Madeira Island (Portugal). Ind. Crops Prod. 2013, 42, 507-512.

(16) Akoh, C. C., Min, D. B., Eds. Food Lipids: Chemistry, Nutrition, and Biotechnology; CRC Press: Boca Raton, FL, USA, 2002; pp 499-683.

(17) Akoh, C. C., Ed. Handbook of Functional Lipids; CRC Press: Boca Raton, FL, USA, 2005; pp 311-457.
(18) Sánchez-Moreno, C.; De Pascual-Teresa, S.; De Ancos, B.; Cano, M. P. Nutritional quality of fruits. In Handbook of Fruits and Fruit Processing; Sinha, N. K., Sidhu, J. S., Barta, J., Wu, J. S. B., Cano, M. P., Eds.; Wiley: Ames, IA, USA, 2012; pp 73-84.

(19) Simopoulos, A. P.; Salem, N., Jr. Purslane: a terrestrial source of omega-3 fatty acids. In Horticulture and Human Health: Contributions of Fruits and Vegetables; Quebedeaux, B., Bliss, F., Eds.; Prentice Hall: Englewood Cliffs, NJ, USA, 1988.

(20) Piironen, V.; Toivo, J.; Puupponen-Pimia, R.; Lampi, A. M. Plant sterols in vegetables, fruits and berries. J. Sci. Food Agric. 2003, 83, 330337.

(21) González-Castejón, M.; Rodriguez-Casado, A. Dietary phytochemicals and their potential effects on obesity: a review. Pharmacol. Res. 2011, 64, 438-455.

(22) Llaverias, G.; Escola-Gil, J. C.; Lerma, E.; Julve, J.; Pons, C.; Cabre, A.; Cofan, M.; Ros, E.; Sanchez-Quesada, J. L.; Blanco-Vaca, F. Phytosterols inhibit the tumor growth and lipoprotein oxidizability induced by a high-fat diet in mice with inherited breast cancer. J. Nutr. Biochem. 2013, 24, 39-48.

(23) Hargrove, J. L.; Greenspan, P.; Hartle, D. K. Nutritional significance and metabolism of very long chain fatty alcohols and acids from dietary waxes. Exp. Biol. Med. 2004, 229, 215-226.

(24) Menéndez, R.; Más, R.; Amor, A. M.; Ledón, N.; Pérez, J.; González, R. M.; Rodeiro, I.; Zayas, M.; Jiménez, S. Inhibition of rat lipoprotein lipid peroxidation by the oral administration of D003, a mixture of very long-chain saturated fatty acids. Can. J. Physiol. Pharmacol. 2002, 80, 13-21.

(25) Fernández-Arche, A.; Marquez-Martín, A.; Vazquez, R. P.; Perona, J. S.; Terencio, C.; Perez-Camino, C.; Ruiz-Gutierrez, V. Longchain fatty alcohols from pomace olive oil modulate the release of proinflammatory mediators. J. Nutr. Biochem. 2009, 20, 155-162.

(26) Chun, J.; Lee, J.; Ye, L.; Exler, J.; Eitenmiller, R. R. Tocopherol and tocotrienol contents of raw and processed fruits and vegetables in the United States diet. J. Food Compos. Anal. 2006, 19, 196-204.

(27) Tiwari, U.; Cummins, E. Fruit and vegetables. In Handbook of Plant Food Phytochemicals: Sources, Stability and Extraction; Tiwari, B. K., Brunton, N. P., Brennan, C., Eds.; Wiley: Oxford, UK, 2013; pp 105137.

(28) Ulatowski, L.; Manor, D. Vitamin E trafficking in neurologic health and disease. Annu. Rev. Nutr. 2013, 33, 87-103. 